\title{
Evaluation of Croatian Development Strategies Using SWOT Analyses with Fuzzy TOPSIS Method and K-Means Methods
}

\author{
Bruno Trstenjak, Andrijana Kos Kavran, and Ivana Bujan
}

\begin{abstract}
The purpose of this paper is to analyse Croatian national development strategy and Croatian local/regional development strategies. Upon defining the purpose we can define the main goal of this paper and which is creation of a tool based on funny logics which will give results on whether the chosen areas of analysed strategies are correspondent or not. For that purposes linguistic variables for areas of importance of national and regional development strategies have been defined with corresponding weight impact factors. Defined areas have been of various development priorities and have been sorted according to SWOT analysis components. Upon definition of variables and weight impact factors the analysis has been conducted.
\end{abstract}

Index Terms - Development strategy, fuzzy TOPSIS, national strategy, k-means clustering.

\section{INTRODUCTION}

To start the story about the national and regional development strategies it is necessary to define personal development. We can say that development enriches the lives of individuals, reduces poverty, and improves well-fare, raises the quality of life in general. As it affects positively the individuals it also positively affects nations and regions. Given this definition of development, it is clear that a development strategy must be focused on transformation of society in identifying the barriers to, as well as potential catalysts for change [1]. When discussing a national level it is clear that the process of creation national and regional development strategy should be planned in details before adoption. National strategies, as well as local/regional strategies should include the component of sustainable development in every sector of an economy. Yet sustainable development touches many sensitive questions and values, therefore progress is somewhat slow [2].

When states and local/regional authorities create development strategies they try to engage as many stakeholders as possible and during the process they create SWOT analysis. SWOT analysis is a marketing tool used in marketing planning but also in many other forms of planning [3]. For the purposes of national SWOT analysis local stakeholder are engaged in the process of strategy

Manuscript received November 5, 2013; revised January 17, 2014.

B. Trstenjak is with the Dept. of Computer Engineering, Medjimurje University of Applied Sciences, Cakovec, Croatia (e-mail: btrstenjak@ mev.hr).

A. K. Kavran and I. Bujan are with the Dept. of Management, Medjimurje University of Applied Sciences, Cakovec, Croatia (e-mail: akos@mev.hr, ibujan@mev.hr). development to contribute with their current issues, expectations and provide possible solutions. However, in some cases there is no correspondence between local/regional and national level. From the aforementioned arises the main goal of this paper, which is to create a tool with the help of fuzzy logics to discover to what extent are areas of Croatian national development strategy correspondent to the areas of local/regional development strategies in Croatia.

The beginnings of fuzzy logics started in 1965 with the creation of fuzzy theory by Lutfi Zadeh [4] as an extended concept to the traditional mathematical binary logics. Fuzzy logic is used in many areas like business management, computer sciences and artificial intelligence. Fuzzy logic presents powerful mathematical tool for modelling of terms whose values are not clearly defined but are expressed in linguistic terms. The logic allows conclusions on the basis of unclear, equivocal and imprecise information.

Fuzzy TOPSIS method is one of the most popular methods used in multi-criteria decision making (MCDM). The method was developed by Hwang \& Yoon (1981). MCDM introduces the concept of criteria, weight values, ranking of alternatives and comparison of alternative solutions according to the ideal solution. The method enables evaluation of alternative solutions, determination of their positive or negative deviations from the ideal solution. According to the methodology of decision making, the best alternative is the one where the deviation is the smallest [5].

When discussing SWOT analysis, the assessment is usually based on the comparison of positive and negative attributes/characteristics. To the assessment of the quality usually influences subjective component of an evaluator. By introducing the fuzzy TOPSIS method we can solve the aforementioned influence and deterministic result is obtained with the help of mathematical model. This article presents the evaluation methods of local strategies and their harmonization with national strategies. The development model of SWOT fuzzy TOPSIS framework is presented, as well as its construction and SWOT analysis methods. This article also describes in a detailed way measurements of SWOT analysis of local development strategies and presents the algorithm of data clustering.

Besides evaluation of development strategies, here are also presented grouping types of SWOT analysis according to mutual characteristics. By using K-means algorithm, clustering of SWOT analysis according to corresponding criteria has been conducted. K-means algorithm enables grouping of objects according to mutual characteristics of all defined criteria. 


\section{NAtional AND Regional DeVElopment StRATEGIES}

\section{A. SWOT Analysis}

SWOT analysis represents the overview of strengths, weaknesses, opportunities and threats. Its execution in all areas of business in crucial, therefore companies, states, non-profit organizations and other organizations create it. The purpose of SWOT analysis is to detect company's position, provide an insight into internal strengths and weakness, as well as external threats and opportunities. Strengths and weaknesses have the greatest influence on company`s success and they are measured according to competence, while opportunities arise when activities in a company benefit the organization [3].

Strategy of development of a country is necessary to define specific areas which are important for growth. Some counties and regions have to prepare development strategies because that is their legal obligation. In their strategies future development is indicated, as well as areas which should be improved. All projects which are submitted for financing have to be harmonized with local development strategy that is they have to support the development of areas defined in the strategy. SWOT analysis is an integral part of development strategies and is made upon overview of capacities of certain region. With SWOT analysis it is possible to define the position of certain region compared to the development of state. The focus is to be put on equal development therefore the harmonization between strategies and SWOT analyses should be made.

\section{B. Development Strategies}

Development strategy of a country has to define specific areas where a country expresses special interest for its development. Development strategies are extremely important and give directions for future investments for a region. Such local development strategies have to be harmonized with national development strategy to enable balanced investments and development of a country.

\section{SWOT FRAMEWORK}

Framework is designed as a tool and support when measuring harmonization of regional development strategy with the guidelines of strategy of a country. Framework consists of few mutually linked modules, which give opportunities to a user to define SWOT analysis, measure SWOT results and make evaluations. Framework is designed in a modular way with a purpose to adapt to user`s needs as much as possible.

\section{A. Framework Structure}

As mentioned earlier in the paper, framework is made of few linked modules. Fig. 1 presents the structure of concept of SWOT framework.

Framework consists of four basic modules: National strategy module, GUI - SWOT module, Fuzzy TOPSIS module and Evaluation strategies module. National strategy module is the first and perhaps the most important module where the whole development strategy starts. The module enables the defining of strategy guidelines of a national development strategy. In the module are defined areas of strategy development on national level, as well as priorities and importance of development of certain areas. Every area of importance doesn't have to have a strong influence in the future development of a country. In this model, the term of importance is connected with weight values, values used in fuzzy TOPSIS module. Defined areas and development priorities are entered in the database. GUI - SWOT module enables to the user definition of individually defined SWOT regional development analysis. In the mentioned module every characteristic in SWOT analysis is connected with national areas and its weight influences on national navel. This connection is very important for later evaluation of certain SWOT analysis. The third module measures SWOT analyses. The module incorporates fuzzy logics and fuzzy membership function which convert linguistic variables/characteristics and crisp values. In the mentioned way the described characteristics of SWOT analysis and criterions become fuzzy numbers suitable for calculations. The second part of the module, TOPSIS method measures SWOT analysis and its harmonization with national strategy, while taking into account the importance of area in a development strategy. The last module is Evaluation strategies module, foreseen for evaluation of SWOT analyses, determination of quality, ranking of SWOT analyses compared to national levels. Module is also foreseen for analysis of similarities of development strategies and their clustering according to defined criterion in particular SWOT analysis.

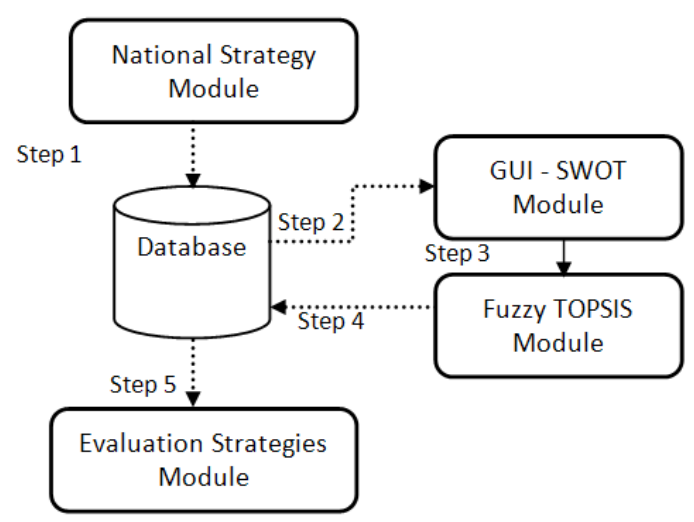

Fig. 1. Framework structure.

\section{B. Fuzzy TOPSIS Model}

The word fuzzy means something unclear, slightly cloudy and foggy. In fuzzy logic membership of an element in a given set is not precisely defined, its membership is expressed in percentages. Membership degree $\mu$ is defined in the interval $\mu \in[0,1]$. The degree of membership is determined by fuzzy membership functions, a higher value defines a higher degree membership of fuzzy set.

Linguistic variables - fuzzy logic uses linguistic variables for describing the input variables and results obtained by fuzzy model. Linguistic variable is presented with a triangular fuzzy number.

Membership function - the function which determines the degree of membership linguistic variables in a fuzzy set. The function must be scaled between the values 0 and 1 .

$$
A \leftarrow\left\{\left(x_{i}, \mu_{A}\left(x_{i}\right) \mid x_{i} \in U\right)\right\}
$$

where the $\mu_{A}(x)$ is a membership function and A is fuzzy set. Membership function value is 


$$
\mu_{A}: X \rightarrow[0,1]
$$

Triangular fuzzy number - number defined by triangular membership function, a triplet $A=(a, b, c)$.

Fuzzy TOPSIS method tries to estimate as far is a particular alternative near the ideal solution. Distance of alternatives can be in positive or negative direction. The method calculates two values: the Fuzzy Positive Ideal Solution (FPIS), which represents a benefit and the Fuzzy Negative Ideal Solution (FNIS), a cost [6], [7].

The mathematics concept of Fuzzy TOPSIS can be described as follows [8]:

Step 1: Determination of Linguistic Terms, Membership Functions and the weighting of evaluation criteria.

Determine the linguistic variables for all criteria. Each linguistic variable is assigned a set of membership functions; determine weights of evaluation criteria and the ratings of alternatives are considered as linguistic terms.

Step 2: Construct the fuzzy decision matrix.

Decision matrix is directly associated with linguistic variables and the criteria alternatives. If assumed that the number of criteria is $\mathrm{n}$ and the count of SWOT analysis is m, fuzzy decision matrix will be obtained with $m$ rows and $n$ columns.

Step 3: Normalize the fuzzy decision matrix.

Normalization of fuzzy decision matrix is accomplished using linear scale transformation. The calculations are done using formulas (3), (4).

$$
\begin{gathered}
\tilde{r}_{i j}=\left(\frac{a_{i j}}{c_{j}^{+}}, \frac{b_{i j}}{c_{j}^{+}}, \frac{c_{i j}}{c_{j}^{+}}\right) \text {and } c_{j}^{+}=\max _{i} c_{i j} \text { (benefit) } \\
\tilde{r}_{i j}=\left(\frac{a_{j}^{-}}{a_{i j}}, \frac{a_{j}^{-}}{b_{i j}}, \frac{a_{j}^{-}}{c_{i j}}\right) \text { and } a_{j}^{-}=\min _{i} a_{i j} \text { (cost) }
\end{gathered}
$$

In quality assessment of SWOT analysis we use the criteria whose value indicates the benefit, we use formula (3).

Step 4: Calculate the weighted fuzzy decision matrix

The weighted normalized fuzzy decision matrix $\mathrm{V}$ is computed by multiplying the weights $\left(w_{j}\right)$ of evaluation criteria with the normalized value $r_{i j}$ from fuzzy decision matrix. The weighted normalized decision matrix $\tilde{V}$ can be represented by Eq. (5):

$$
\tilde{V}=\left[\tilde{v}_{i j}\right]_{n \times j}, i=1,2, \ldots, n ; j=1,2, \ldots, J
$$

where

$$
\tilde{v}_{i j}=\tilde{r}_{i j}(\cdot) \widetilde{w}_{i}
$$

Step 5: Determine the fuzzy positive-ideal solution (FPIS $A+$ ) and fuzzy negative-ideal solution (FNIS $A$-)

According to the weighted normalized fuzzy decision matrix, in this step we determine the positive and negative displacement from the ideal solution. Their ranges belong to the closed interval $[0,1]$.

Step 6: Calculate the distance of each alternative from FPIS and FNIS

The distance $\left(d_{j}^{+}\right.$and $\left.d_{j}^{-}\right)$of each alternative $A^{+}$from and $A^{-}$ can be calculated as:

$$
d_{i}^{+}=\sum_{j=1}^{n} d\left(\tilde{v}_{i j}, \tilde{v}_{j}^{+}\right), i=1,2, \ldots, m
$$

$$
d_{i}^{-}=\sum_{j=1}^{n} d\left(\tilde{v}_{i j}, \tilde{v}_{j}^{-}\right), i=1,2, \ldots, m
$$

The distance between two fuzzy numbers $\tilde{a}=\left(a_{1}, a_{2}, a_{3}\right)$ and $\tilde{b}=\left(b_{1}, b_{2}, b_{3}\right)$, can be calculated as:

$d_{v}(\tilde{a}, \tilde{b})=\sqrt{\frac{1}{3}\left[\left(a_{1}-b_{1}\right)^{2}+\left(a_{2}-b_{2}\right)^{2}+\left(a_{3}-b_{3}\right)^{2}\right]}$

Step 7: Calculate the closeness coefficient

The closeness coefficient $C C_{i}$ is defined to determine the ranking order of all alternatives. The index $C C_{i}$ indicates that the alternative is close to the $\operatorname{FPIS}\left(d_{i}^{+}\right)$and far from the FNIS $\left(d_{i}^{-}\right)$. The closeness coefficient of each evaluated teacher quality can be calculated as [9], [10]:

$$
C C_{i}=\frac{d_{i}^{-}}{d_{i}^{-}+d_{i}^{+}}
$$

\section{Linguistic Variables and Importance Weights}

In order to determine the quality of regional strategy based on defined guidelines of a national strategy, it is necessary to define linguistic variables which will describe values, assessment criteria and fuzzy membership functions. With the help of fuzzy membership function the importance of specific development area on national level is defined, as well as weight of influence of certain characteristic in SWOT analysis. Functions are used to determine the value of final assessment of strategy evaluation. Table I presents importance weights of national priority areas and Table II presents linguistic variables for evaluation of influence of characteristic/criteria entered in SWOT analysis.

TABLE I: LINGUISTIC VARIABLES FOR AREAS OF IMPORTANCE NATIONAL DEVELOPMENT STRATEGIES

\begin{tabular}{|l|c|}
\hline \multicolumn{1}{|c|}{ Linguistic variables } & $\begin{array}{c}\text { Fuzzy number } \\
\text { (weight) }\end{array}$ \\
\hline Less important (L) & $(1.0,2.5,4.0)$ \\
\hline Average importance (A) & $(3.0,5.0,7.0)$ \\
\hline Very important (V) & $(6,0,8.0,10.0)$ \\
\hline
\end{tabular}

TABLE II: LINGUISTIC VARIABLES FOR IMPORTANCE WEIGHT FOR SWOT ANALYSIS

\begin{tabular}{|l|c|}
\hline \multicolumn{1}{|c|}{ Linguistic variables } & $\begin{array}{c}\text { Fuzzy number } \\
\text { (weight) }\end{array}$ \\
\hline Small Impact (SI) & $(1.0,2.5,4.0)$ \\
\hline Medium Impact (MI) & $(3.0,5.0,7.0)$ \\
\hline Large Impact (LI) & $(6,0,8.0,10.0)$ \\
\hline
\end{tabular}

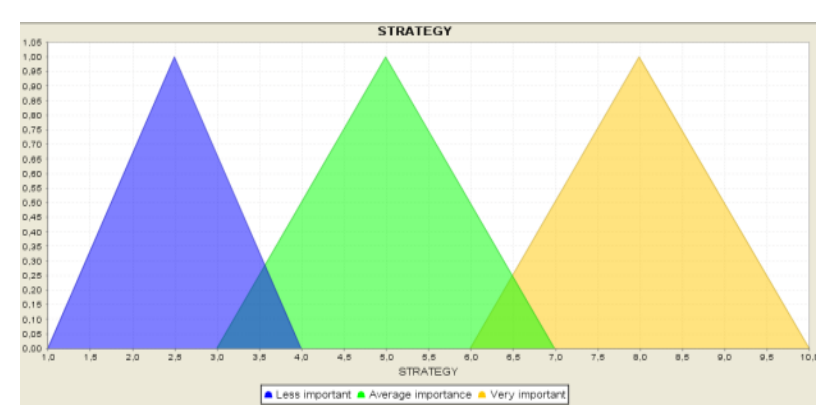

Fig. 2. The fuzzy membership function. 
The fuzzy membership functions for the national development strategies importance are shown in Fig. 2.

\section{FrameWORK EVALUATION}

For the purposes of this article we will define the importance areas of the national development strategy and its importance weights, as presented in the Table III. Table III presents six areas of strategy development, foreseen guidelines and the importance of investment on national level. All areas don't possess equal development priorities. In the column "weight" weight importance is listed. Areas are taken from the Croatian development strategy [11].

TABLE III: AREAS OF NATIONAL DEVELOPMENT STRATEGY AND IMPORTANCE WEIGHT

\begin{tabular}{|c|l|l|}
\hline Label & \multicolumn{1}{|c|}{ Area } & \multicolumn{1}{c|}{ Weight } \\
\hline$A 1$ & Export & Very important \\
\hline$A 2$ & Competitiveness & Very important \\
\hline$A 3$ & Employment & Average importance \\
\hline$A 4$ & Research and Innovation & Average importance \\
\hline$A 5$ & Infrastructure & Less important \\
\hline$A 6$ & Entrepreneurship & Less important \\
\hline
\end{tabular}

For the purposes of evaluation, two SWOT analyses have been defined; SWOT analysis $A$ [12] and SWOT analysis $B$ [13] which contain various criterion of different influence and area of SWOT analysis. Every criterion is connected to an area of importance of national strategy. Table $\mathrm{V}$ and Table VI present SWOT analyses. By the name of criterion a mark of the area of national strategy is attached, and in the separate column a mark of importance weight of criteria on regional development is entered. Influence can be positive or negative depending on where the criterion is mentioned in SWOT analysis.

TABLE IV: $A$ - SWOT ANALYSIS AND CRITERION IMPACT

\begin{tabular}{|c|c|}
\hline Criteria $\rightarrow$ Area of national interest & Impact \\
\hline \multicolumn{2}{|l|}{ STRENGTHS } \\
\hline C1- The educational structure of the population $\rightarrow \boldsymbol{A 3}$ & MI \\
\hline C2- Craftsmanship $\rightarrow \boldsymbol{A 1}$ & MI \\
\hline \multicolumn{2}{|l|}{ OPPORTUNITIES } \\
\hline C3- Demand for ecological products $\rightarrow \boldsymbol{A 1}$ & MI \\
\hline C4- Projects for EU funds $\rightarrow \boldsymbol{A 5}$ & LI \\
\hline \multicolumn{2}{|l|}{ WEAKNESSES } \\
\hline C5- Labor force with experience $\rightarrow \boldsymbol{A 3}$ & SI \\
\hline C6- Transport infrastructure $\rightarrow \boldsymbol{A 5}$ & MI \\
\hline C7- The synergy between the economy and research $\rightarrow A \mathbf{4}$ & SI \\
\hline C8- The unemployment rate $\rightarrow \boldsymbol{A 3}$ & LI \\
\hline \multicolumn{2}{|l|}{ THREATS } \\
\hline C9- Market competition $\rightarrow \boldsymbol{A 2}$ & LI \\
\hline C10- The stimulation of exports $\rightarrow \boldsymbol{A 3}$ & LI \\
\hline
\end{tabular}

Both abovementioned analyses are very similar according to number and types of criteria. However, defined criteria belong to various areas of national development strategy and have different level of positive or negative influence on general evaluation of development strategy.

TABLE V: $B$ - SWOT ANALYSIS AND CRITERION IMPACT

\begin{tabular}{|l|c|}
\hline Criteria $\rightarrow$ Area of national interest & Impact \\
\hline STRENGTHS & MI \\
\hline C1- Economic zones $\rightarrow \boldsymbol{A 6}$ & LI \\
\hline C2- Foreign companies $\rightarrow \boldsymbol{A 1}$ & SI \\
\hline C3- Cross-border cooperation $\rightarrow \boldsymbol{A 2}$ & LI \\
\hline OPPORTUNITIES & MI \\
\hline C4- Geographical position $\rightarrow \boldsymbol{A 5}$ & MI \\
\hline C5- Clustering $\rightarrow \boldsymbol{A 4}$ & SI \\
\hline WEAKNESSES & SI \\
\hline C6- Culture of innovation $\rightarrow \boldsymbol{A 4}$ & \multicolumn{2}{|l|}{} \\
\hline C7- Public transport $\rightarrow \boldsymbol{A 6}$ & MI \\
\hline C8- Labor productivity $\rightarrow \boldsymbol{A 2}$ & LI \\
\hline THREATS &
\end{tabular}

\section{ILLUSTRATIVE EXAMPLE}

This example will present evaluation of SWOT analysis results of regional development strategies and harmonization with national development priorities. Also, the example will illustrate application of one algorithm of clustering of SWOT analysis based on the criterion and importance.

\section{A. Regional SWOT Analysis}

TABLE VI: SWOT CRITERIA, ITS IMPACT IN NATIONAL AREA

\begin{tabular}{|c|c|c|c|c|}
\hline Criteria & SWOT & Impact & Area & Benefit/Cost \\
\hline \multirow{2}{*}{ C1 } & SWOT A & MI & $A 3$ & Benefit \\
\hline & SWOT B & MI & $A 6$ & Benefit \\
\hline \multirow{2}{*}{$\mathrm{C} 2$} & SWOT A & MI & $A 1$ & Benefit \\
\hline & SWOT B & LI & $A 1$ & Benefit \\
\hline \multirow{2}{*}{ C3 } & SWOT A & MI & $A 1$ & Benefit \\
\hline & SWOT B & SI & $A 2$ & Benefit \\
\hline \multirow{2}{*}{$\mathrm{C} 4$} & SWOT A & LI & $A 5$ & Benefit \\
\hline & SWOT B & LI & $A 5$ & Benefit \\
\hline \multirow{2}{*}{ C5 } & SWOT A & SI & $A 3$ & Cost \\
\hline & SWOT B & MI & $A 4$ & Benefit \\
\hline \multirow{2}{*}{ C6 } & SWOT A & MI & $A 5$ & Cost \\
\hline & SWOT B & MI & $A 4$ & Cost \\
\hline \multirow{2}{*}{ C7 } & SWOT A & SI & $A 4$ & Cost \\
\hline & SWOT B & SI & $A 6$ & Cost \\
\hline \multirow{2}{*}{ C8 } & SWOT A & LI & $A 3$ & Cost \\
\hline & SWOT B & SI & $A 2$ & Cost \\
\hline \multirow{2}{*}{ C9 } & SWOT A & LI & $A 2$ & Cost \\
\hline & SWOT B & MI & $A 3$ & Cost \\
\hline \multirow{2}{*}{ C10 } & SWOT A & LI & $A 3$ & Cost \\
\hline & SWOT B & LI & $A 3$ & Cost \\
\hline
\end{tabular}

Previous chapter shows two SWOT analyses, shortened test versions. Every SWOT analysis contains various criteria of evaluation, depending on the situation in particular region. Table VI presents criteria, their influence in specific part of SWOT analysis and importance weight depending on the area of national strategy to which a certain criterion belongs. Criteria listed in Strengths and Opportunities part of analysis represent in TOPSIS method a benefit and other criteria are 
considered a cost in calculation area. Term cost will be considered as negative element which reduces the value of development strategy in this particular case. Benefit will be calculated according to Eq. (3) and cost according to Eq. (4). These two values will determine the final distance of regional strategy towards an ideal solution, ideal development strategy.

\section{B. Fuzzy - TOPSIS Evaluation}

Upon determination of linguistic variables it is necessary to adjust variable to the model, which will enable the evaluation and calculation of final grade of analysis. By using previously defined fuzzy membership functions, fuzzy number, interval of activity and importance weight of criteria will be defined according to Table III, national strategy importance weight as shown in Table VII.

TABLE VII: THE IMPORTANCE WEIGHT OF EACH CRITERION GIVEN BY FUZZY MEMBERSHIP FUNCTIONS

\begin{tabular}{|c|c|c|c|}
\hline Criteria & SWOT & $\begin{array}{c}\text { Impact } \\
\text { Fuzzy number }\end{array}$ & $\begin{array}{c}\text { Area } \\
\text { Fuzzy number } \\
\text { (weight) }\end{array}$ \\
\hline \multirow{2}{*}{ C1 } & SWOT A & $(3.0,5.0,7.0)$ & $(3.0,5.0,7.0)$ \\
\hline & SWOT B & $(3.0,5.0,7.0)$ & $(1.0,2.5,4.0)$ \\
\hline \multirow{2}{*}{$\mathrm{C2}$} & SWOT A & $(3.0,5.0,7.0)$ & $(6,0,8.0,10.0)$ \\
\hline & SWOT B & $(6,0,8.0,10.0)$ & $(6,0,8.0,10.0)$ \\
\hline \multirow{2}{*}{ C3 } & SWOT A & $(3.0,5.0,7.0)$ & $(6,0,8.0,10.0)$ \\
\hline & SWOT B & $(1.0,2.5,4.0)$ & $(6,0,8.0,10.0)$ \\
\hline \multirow{2}{*}{$\mathrm{C4}$} & SWOT A & $(6,0,8.0,10.0)$ & $(1.0,2.5,4.0)$ \\
\hline & SWOT B & $(6,0,8.0,10.0)$ & $(1.0,2.5,4.0)$ \\
\hline \multirow{2}{*}{ C5 } & SWOT A & $(1.0,2.5,4.0)$ & $(3.0,5.0,7.0)$ \\
\hline & SWOT B & $(3.0,5.0,7.0)$ & $(3.0,5.0,7.0)$ \\
\hline \multirow{2}{*}{ C6 } & SWOT A & $(3.0,5.0,7.0)$ & $(1.0,2.5,4.0)$ \\
\hline & SWOT B & $(3.0,5.0,7.0)$ & $(3.0,5.0,7.0)$ \\
\hline \multirow{2}{*}{ C7 } & SWOT A & $(1.0,2.5,4.0)$ & $(3.0,5.0,7.0)$ \\
\hline & SWOT B & $(1.0,2.5,4.0)$ & $(1.0,2.5,4.0)$ \\
\hline \multirow{2}{*}{ C8 } & SWOT A & $(6,0,8.0,10.0)$ & $(3.0,5.0,7.0)$ \\
\hline & SWOT B & $(1.0,2.5,4.0)$ & $(6,0,8.0,10.0)$ \\
\hline \multirow{2}{*}{ C9 } & SWOT A & $(6,0,8.0,10.0)$ & $(6,0,8.0,10.0)$ \\
\hline & SWOT B & $(3.0,5.0,7.0)$ & $(3.0,5.0,7.0)$ \\
\hline \multirow{2}{*}{$\mathrm{C10}$} & SWOT A & $(6,0,8.0,10.0)$ & $(3.0,5.0,7.0)$ \\
\hline & SWOT B & $(1.0,2.5,4.0)$ & $(3.0,5.0,7.0)$ \\
\hline
\end{tabular}

Out of deteriorated fuzzy values, a decision matrix has been defined that has to be normalized and included in the importance weights of particular areas of national strategy to which a certain criteria corresponds to. Before the calculation of quality of development strategy it is necessary to normalize decision matrix and include importance weight.

The normalized decision matrix can be calculated by applying Eq. (3) or Eq. (4) depending on whether the criterion in SWOT analysis is a benefit or a cost, as shown in Table IX.

After decision matrix normalization, the next step is to calculate the weighted fuzzy decision matrix. Upon normalization the next step is approached and that is calculation of closeness coefficients. The closeness coefficients for each regional development strategy are calculated by applying Eq. (10) as shown in Table IX.

When we look at the original data of both SWOT analyses it is possible to conclude that they are quite similar and relatively equal. In this case, user would have difficulties to determine which strategy is better. Obtained data show that
SWOT $B$ analysis of regional strategy is better and closer to development guidelines of national strategy. The reason for that result can be found in low values, which with the stress put on importance give an advantage to SWOT $B$ analysis.

TABLE VIII: NORMALIZED AGGREGATION FUZZY DECISION MATRIX

\begin{tabular}{|c|c|c|c|}
\hline Criteria & SWOT & $\begin{array}{c}\text { Impact } \\
\text { Fuzzy number }\end{array}$ & Benefit/Cost \\
\hline \multirow{2}{*}{ C1 } & SWOT A & $(0.4,0.7,1.0)$ & Benefit \\
\hline & SWOT B & $(0.4,0.7,1.0)$ & Benefit \\
\hline \multirow{2}{*}{$\mathrm{C2}$} & SWOT A & $(0.4,0.7,1.0)$ & Benefit \\
\hline & SWOT B & $(0.6,0.8,1.0)$ & Benefit \\
\hline \multirow{2}{*}{$\mathbf{C 3}$} & SWOT A & $(0.43,0.7,1.0)$ & Benefit \\
\hline & SWOT B & $(0.25,0.63,1.0)$ & Benefit \\
\hline \multirow{2}{*}{$\mathrm{C4}$} & SWOT A & $(0,6,0.8,1.0)$ & Benefit \\
\hline & SWOT B & $(0.6,0.8,1.0)$ & Benefit \\
\hline \multirow{2}{*}{ C5 } & SWOT A & $(1.0,0.4,0.25)$ & Cost \\
\hline & SWOT B & $(0.43,0.7,1.0)$ & Benefit \\
\hline \multirow{2}{*}{ C6 } & SWOT A & $(1.0,0.6,0.43)$ & Cost \\
\hline & SWOT B & $(1,0,0.6,0.43)$ & Cost \\
\hline \multirow{2}{*}{ C7 } & SWOT A & $(1.0,0.4,0.25)$ & Cost \\
\hline & SWOT B & $(1.0,0.4,0.25)$ & Cost \\
\hline \multirow{2}{*}{ C8 } & SWOT A & $(1,0,0.75,0.6)$ & Cost \\
\hline & SWOT B & $(1,0,0.4,0.25)$ & Cost \\
\hline \multirow{2}{*}{ C9 } & SWOT A & $(1,0,0.75,0.6)$ & Cost \\
\hline & SWOT B & $(1.0,0.6,0.43)$ & Cost \\
\hline \multirow{2}{*}{ C10 } & SWOT A & $(1,0,0.75,0.6)$ & Cost \\
\hline & SWOT B & $(1,0,0.4,0.25)$ & Cost \\
\hline
\end{tabular}

TABLE IX: FUZZY TOPSIS RESULT

\begin{tabular}{|c|c|c|c|c|}
\hline SWOT & $\boldsymbol{d}_{\boldsymbol{j}}^{+}$ & $\boldsymbol{d}_{\boldsymbol{j}}^{-}$ & $\boldsymbol{C C}_{\boldsymbol{i}}$ & Rating \\
\hline SWOT A & 31,073 & 40,231 & 0,56421 & 2 \\
\hline SWOT B & 28,019 & 36,931 & 0,56861 & 1 \\
\hline
\end{tabular}

\section{K-Means Clustering}

Clustering belongs to the area of data analysis and machine learning domain. Many methods are used for data organization in clusters according to their similarities. The clustering process is usually based on measuring similarities of attributes in data [14].

$\mathrm{K}-\mathrm{Means}$ algorithm is one of the popular unsupervised learning algorithms, relatively easy for implementation. The basic idea is to define $k$ centroids, one for each cluster. Controids represent the points of gravitation around which the elements are grouped according to their similarities. Usually there are multi-dimensional data like in the SWOT analyses cases. Algorithm calculates the distance between individual elements from the set centroids, while algorithm corrects the position of centroids in every iteration of algorithm repetition. The idea with this algorithm is not to overlap the clusters.

The algorithm calculates the distance between the points by the means of Euclid's distance. It uses the function that defines minimal sum of the mean square errors on all $K$ clusters [15]. The mean square error can be calculated as:

$$
J\left(C_{k}\right)=\sum_{x_{i} \in c_{k}}\left\|x_{i}-\mu_{k}\right\|^{2}
$$

where $x_{i}$ is data point, $\mu_{k}$ is cluster center,

The goal of k-means is to minimize the sum of the squared error over all K clusters [9], 


$$
J(C)=\sum_{k=1}^{K} \sum_{x_{i} \in c_{k}}\left\|x_{i}-\mu_{k}\right\|^{2}
$$

Croatia is currently divided into 22 regions. Besides the analysis of harmonization of regional strategies with the national, it is also very important to discover their similarities. Every region possesses certain specificities and special requirements and that can cause the situation where a certain regional strategy isn't correspondent to a national strategy. Before clustering process it is necessary to adjust linguistic variables and fuzzy values in decision matrix to crisp values for every particular criteria in SWOT analysis.

There exist several available methods, in this paper we use the expected value [D. Dubois, H. Prade, 1987; S. Heilpern, 1992] calculated as [16]:

$$
E V(A)=\frac{a+2 b+c}{4}
$$

where $T$ is fuzzy number triplet $A=(a, b, c)$.

The example presents the clustering of 22 different regional SWOT analyses. Analysed data will be grouped in three $(K=3)$ clusters according to their similarities.

The fuzzy number transformation and expected value for previous SWOT analysis is calculated by applying Eq. (12) as shown in Table X.

For the purposes of clustering calculation and analysis WEKA $^{1}$ and MatLab machine learning software virtual tool have been used. The following results have been obtained by classification and have been presented in Table XI.

TABLE X: DECISION MATRIX WITH TRANSFORMED FUZZY VALUES IN TO

\begin{tabular}{|c|c|c|}
\hline \multicolumn{3}{|c|}{ CRISP VALUES } \\
\hline Criteria & $\begin{array}{c}\text { SWOT A } \\
\text { EV }\end{array}$ & $\begin{array}{c}\text { SWOT B } \\
\text { EV }\end{array}$ \\
\hline C1 & 27 & 14 \\
\hline C2 & 42 & 66 \\
\hline C3 & 42 & 21,5 \\
\hline C4 & 21,5 & 46,5 \\
\hline C5 & 14 & 27 \\
\hline C6 & 14 & 27 \\
\hline C7 & 14 & 7,5 \\
\hline C8 & 42 & 21,5 \\
\hline C9 & 66 & 27 \\
\hline C10 & 42 & 14 \\
\hline
\end{tabular}

TABLE XI: RESULTS OF 22 SWOT ANALYSIS CLASSIFICATION

\begin{tabular}{|ll|ll|}
\hline \multicolumn{2}{|c|}{ Cluster centroids } & \multicolumn{2}{c|}{ Clustered Instances } \\
\hline Attribute & Full Data (22) & & \\
Cluster 1 & $(3)$ & Cluster 1 & $3(14 \%)$ \\
Cluster 2 & $(4)$ & Cluster 2 & $4(18 \%)$ \\
Cluster 3 & $(15)$ & Cluster 3 & $15(68 \%)$ \\
\hline
\end{tabular}

Results indicate that majority of the regional strategies are grouped in third cluster.

Fig. 3 presents classification of SWOT analyses in clusters

${ }^{1}$ WEKA - Waikato Environment for Knowledge Analysis. Machine learning software developed at the University of Waikato on test data according to chosen criteria. We can notice relatively good distribution of development strategies. Obtained clusters are relatively "clear". In our example, SWOT $A$ analysis has been put in cluster 1 , while SWOT $B$ has been put in cluster 2 .

These results have confirmed previously mentioned results that the two mentioned development strategies significantly differ. Not just according to the quality, but also according to national development strategies and their development character.

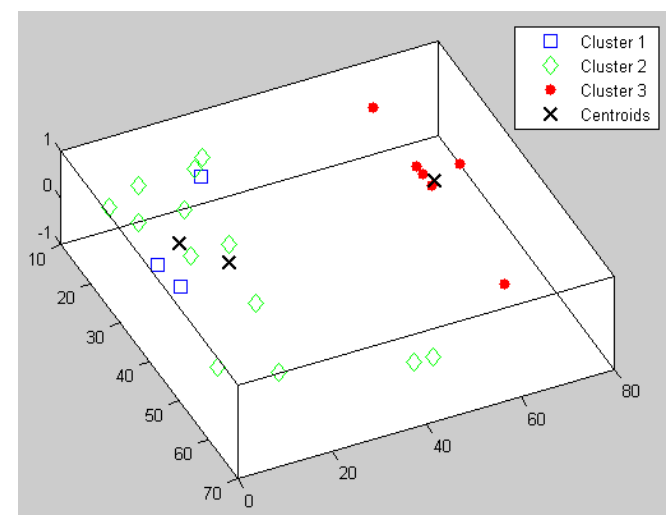

Fig. 3. K-means clustered results.

\section{CONCLUSION}

This paper has showed that fuzzy TOPSIS method is an effective tool for determination of quality of local/regional SWOT analyses and their harmonization with national priorities. By using the method in this paper we have obtained closeness coefficients, which have to be in the range between 0 and 1 for every SWOT analysis. Accordingly, SWOT analysis $B$ has had higher closeness coefficient which means that the mentioned SWOT analysis is better and closer to development guidelines of national strategy. The reason for that result could be found in importance weights which give advantage to SWOT $B$ analysis compared to SWOT $A$ analysis.

The other method of clustering produced results which have proved the results of fuzzy TOPSIS method with which has been confirmed that SWOT analysis $A$ and SWOT analysis $B$ differ according to quality, harmonization with national development strategy and according to development character. That way, the clustering method has shown that SWOT analysis $A$ has been put in first cluster while SWOT analysis $B$ has been put in third cluster.

This approach can be used to evaluate any areas of development strategies where linguistic variables can be set as well as other fields that can be compared with higher areas of importance.

As Croatian regional development strategies are made until the end of 2013 and new ones are in the making process, it would be interesting to include given methods to evaluate them before they are finished. This way they could be harmonized with national strategy.

\section{REFERENCES}

[1] J. E. Sliglitz, "Towards a new paradigm for development strategies, policies and processes," Given as the 1998 Prebisch Lecture at UNCTAD, Geneva, October 19, 1998, pp. 3. 
[2] D. Swanson, L. Pinter, F. Bregha et al., National Strategies for Sustainable Development, International institute for sustainable development, 2004, p. ix.

[3] P. Kotler, V. Wong, J. Saunders, and G. Armstrong, "Principles of marketing," MATE d.o.o. Zagreb, 2006.

[4] L. A. Zadeh, Fuzzy Sets. Inform, and Control 8, 1965, pp. 338-353.

[5] M. Momeni, M. R. Fathi, M. K. Zarchi, and S. Azizollahi, A Fuzzy TOPSIS-Based Approach to Maintennance Strategy Selection: A Case Study.

[6] M. A. Aref, N. Javadian, and M. Kazemi, A New Fuzzy Positive and Negative Ideal Solution for Fuzzy TOPSIS, Wseas Transactions on Circuits and Systems, 2012, issue 3, vol. 11.

[7] S. Uyun and I. Riadi, "A fuzzy topsis multiple-attribute decision making for scholarship selection," Telekomnika, 2011, vol. 9, no. 1, pp. 37-46.

[8] Y.-L. Cheng, Y. H. Lin, and M. L. Tseng, "Analysis of hotel service quality perceptions using fuzzy TOPSIS," Progress in Business Innovation and Technology Management 001, pp. 90-109, 2011.

[9] C.-C. Sun and G. T. R. Lin, "Using fuzzy TOPSIS method for evaluating the competitive advantages of shopping websites," Expert Systems with Applications, vol. 36, pp. 11764-11771, 2009.

[10] M. Yazdani, A. Alidoosti, and M. H. Basiri, "Risk analysis for critical infrastructures using fuzzy TOPSIS," Journal of Management Research, vol. 4, no. 1: E6, 2012.

[11] Regional Development Strategy of Republic of Croatia 2011-2013. [Online]. Available: http://www.mrrfeu.hr/UserDocsImages/STRATEGIJA_REGIONAL NOG_RAZVOJA.pdf

[12] Development Strategy of Virovitica-Podravina County 2011-2013. [Online].

Available: http://www.vpz.com.hr/wp-content/uploads/2011/01/\%C5\%BDRS-V P\%C5\%BD-2011-2013.pdf

[13] Development Strategy of Medjimurje County 2011-2013. [Online]. Available:

http://www.redea.hr/images/stories/razno/razvojna-strategija-medjimu rske-zupanije-2011-2013.pdf

[14] T. Velmurugan and T. Santhanam, "Performance evaluation of k-means and fuzzy c-means clustering algorithms for statistical distributions of input data points," European Journal of Scientific Research, vol. 46, no. 3, pp. 320-330, 2010

[15] A. K. Jain, "Data clustering: 50 years beyond K-means," Pattern Recognition Letters, vol. 31, pp. 651-666, 2010

[16] O. I. Ban and N. Bugnar, "Using triangular fuzzy number for measuring quality of sevice from the client's perspective in the hotel industry," Fascicle of Management and Technological Engineering, vol. VI (XVI), 2007.

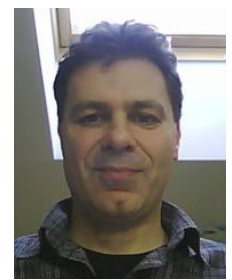

Bruno Trstenjak is a lecturer at the Medjimurje University of Applied Sciences in Cakovec, Croatia In 2012, he completed MSc degree in the field of computer sciences at the Faculty of Electrical Engineering in Sarajevo, BiH. Since 2008, he has worked as an academic member at the Medjimurje University of Applied Sciences, where he has been involved in lecturing several courses in fields of computer Sciences. His area of interest covers: programming and application development, field of artificial intelligence, machine learning and data mining. He has been involved in the several EU projects in the field of education, as a project manager or a member. Recently, he is head of department at professional study program - Computer Engineering.

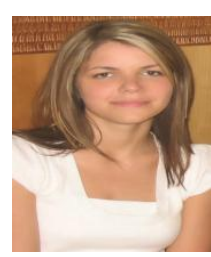

Andrijana Kos Kavran is a lecturer at the Medjimurje University of Applied Sciences in Cakovec, Croatia, department of Management in tourism and sports, holding lectures in basics of marketing, tourism marketing, sports marketing, and market research. She gained the title Bachelor of Science in marketing field in 2006 at the Faculty of Economics in Zagreb, Croatia. She is currently enrolled in PhD study at the Faculty of Economics Rijeka, Croatia. Her current and previous research interests include strategic and tactic marketing. She worked as sales and purchase assistant at Hespo Ltd. from 2006 until 2008, as marketing manager at Bat Ltd from 2008 until 2010

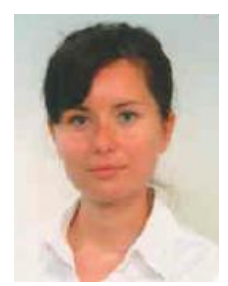

Ivana Bujan is a lecturer at the Medjimurje University of Applied Sciences in Cakovec, Croatia, department of Management in tourism and sports, holding lectures in corporate finance, basics of accounting, entrepreneurship and operational planning. Her fields of interest are finances, especially finance of SME sector and ventures, capital structure, bond financing and translation sciences. She gained the title of Bachelor of Science in finance in 2006 at the Faculty of Economics in Zagreb, Croatia and Master of Arts in 2010 at the Faculty of Humanities and Social Sciences in Zagreb in the field of philology, English language. She is currently enrolled in Ph.D. study program at the Faculty of Economics Rijeka, Croatia Previous work experience include work as external lecturer at the Faculty of Economics in Zagreb, lecturer of business English in Foreign language centre Memento in Cakovec, teacher of English in Primary school in Kursanec, Croatia, production planning in company Haix Ltd. Croatia, sales assistant and translator in company BU-net Ltd. Croatia. 